\title{
Efeitos da Consultoria Colaborativa com familiares na prevenção de problemas comportamentais infantis
}

\author{
Effects of collaborative consulting with relatives on the prevention of child behavioral problems
}

\author{
Aline Maira da Silva ${ }^{\left[{ }^{[a]}\right.}$, Enicéia Goncalves Mendes ${ }^{[b]}$
}

\footnotetext{
${ }^{[a]}$ Doutora em Educação Especial pela Universidade Federal de São Carlos (UFSCar), professora adjunta da Faculdade de Educação da Universidade Federal da Grande Dourados (FAED/UFGD), Dourados, MS Brasil, e-mail:

alinesilva@ufgd.edu.br

${ }^{[b]}$ Doutora em Psicologia, professora adjunta do Departamento de Psicologia da Universidade Federal de São Carlos (UFSCar), Programa de Pós-Graduação em Educação Especial (PPGEEs/UFSCar), São Carlos, SP - Brasil, e-mail: egmendes@ufscar.br
}

Recebido 10/02/2012 Received: 02/10/2012

Aprovado: 24/04/2012 Approved: 04/22/2012

\begin{abstract}
Resumo
As intervenções voltadas para a prevenção de problemas comportamentais desenvolvidas no ambiente escolar nem sempre são suficientes quando os determinantes dos problemas estão relacionados também ao contexto familiar. Este relato é baseado em um estudo cujo objetivo foi desenvolver, implementar e avaliar um programa de intervenção baseado no modelo de Consultoria Colaborativa Escolar, voltado para prevenir problemas comportamentais. 0 estudo envolveu professores, alunos e familiares, mas no presente relato enfocamos a intervenção desenvolvida com os 18 familiares participantes. 0 local do estudo foi uma escola municipal de Ensino Fundamental, localizada no interior do estado de São Paulo. Foram conduzidas três etapas: 1) aplicação do Inventário de Estilos Parentais (IEP); 2) programa de intervenção; 3) avaliação do programa (reaplicação do IEP e reunião de grupo focal). Após a intervenção houve aumento estatisticamente significativo nas práticas de monitoria positiva e comportamental moral, e diminuição estatisticamente significativa na disciplina relaxada e na monitoria negativa. Conclui-se que a Consultoria Colaborativa pode ser um modelo promissor para basear intervenções voltadas para melhorar práticas parentais e, consequentemente, prevenir problemas comportamentais.
\end{abstract}

Palavras-chave: Prevenção primária. Família. Transtornos do comportamento infantil.

\begin{abstract}
The interventions directed to the prevention of behavior problems developed in the school environment are not always adequate, when the determining factors of the problems are also related to the family context. This report is based on a study whose aim was to develop, implement and assess an intervention program based on the Educational Collaborative Consulting model, aimed at preventing behavior problems. The study involved teachers, students and relatives, only for this present report we have focused on the intervention carried on the 18 participant relatives. The study place was a public elementary school located within the state of São Paulo. Three stages were conducted: 1) application of the Parental Style Inventory (PSI); 2) intervention program; 3) program assessment (reapplication of the PSI and focal group meeting). After the intervention, there was a statistically significant increase of positive monitoring practices
\end{abstract}


and moral behavior, and a statistically significant decrease of loose discipline and negative monitoring. We conclude that the Collaborative Consulting can be a promising model to base interventions aimed at improving parenting practices on, and, consequently, to prevent behavior problems.

Keywords: Primary prevention. Family. Child behavior disorders.

\section{Introdução}

Os problemas comportamentais infantis, incluindo os disciplinares, representam um grande desafio a ser enfrentado nas escolas, pois muitas vezes os determinantes dos comportamentos indesejáveis são complexos e extrapolam o contexto escolar. As práticas educativas utilizadas pelos pais têm grande influência na ocorrência de problemas de comportamento apresentados pelos filhos e, ao mesmo tempo, professores, colegas e vizinhos que fazem parte do ambiente da criança podem apresentar as condições que propiciam ou mantêm comportamentos indesejáveis. Em vista disso, os problemas de comportamento não devem ser considerados simplesmente como ações inapropriadas das crianças, mas como interações inadequadas entre essas crianças e outras pessoas (Kauffman, 2005).

Pais que disciplinam seus filhos de modo efetivo são sensíveis para suas necessidades, empáticos e atenciosos, estabelecem com eles um padrão de interações positivas e recíprocas, utilizam o entusiasmo, a cordialidade e a reciprocidade como base para estabelecer vínculos emocionais ou regras. Esses pais também monitoram seus filhos por meio de supervisão apropriada e enfrentam comportamentos inadequados diretamente e constantemente, ao invés de tentar manipular ou coagir seus filhos. Tais pais fornecem instruções não ambíguas e fazem exigências de modo firme, mas não hostil, e apresentam consequências negativas, mas não abusivas, para comportamentos inadequados. Esses pais fornecem encorajamento, elogio, aprovação e outras recompensas para os comportamentos desejáveis de seus filhos (Gomide, 2004; Weber, 2007).

Entretanto, nem sempre os pais estão preparados para enfrentar a tarefa de educar seus filhos. Segundo Kauffman (2005), a modelação, o reforço e a punição por parte dos pais em relação aos comportamentos apresentados pelos filhos indicam como a família influencia o comportamento de uma criança. Dessa forma, segundo o mesmo autor, pais podem fazer uso de práticas disciplinares ineficazes porque eles não têm habilidade ou não estão dispostos a impor limites consistentes, estáveis e não ambíguos.

De acordo com Salvo, Silvares e Toni (2005), práticas parentais de monitoria positiva e comportamento moral estão relacionados com comportamentos pró-sociais. Por outro lado, a ausência de tais práticas, associadas a abuso físico, negligência, monitoria negativa, punição inconsistente e/ou disciplina relaxada, são situações preditoras de problemas de comportamento.

Em vista disso, é importante investigar a eficácia de intervenções com familiares voltadas para ensinar aos pais como utilizar práticas educativas adequadas e, consequentemente, prevenir a manifestação de problemas comportamentais por parte dos filhos. No presente estudo, procurou-se avaliar os efeitos de um programa de intervenção baseado no modelo de Consultoria Colaborativa Escolar (CCE). De acordo com Kampwirth (2003), a CCE é um processo no qual um consultor trabalha em uma relação igualitária e não hierárquica com um consultante (professores e pais, por exemplo), visando reunir seus esforços para tomar decisões e implementar intervenções que melhor atendam aos interesses dos alunos.

A CCE apresenta benefícios para todos os envolvidos no processo: oportunidade de compartilhar habilidades; aumento na comunicação entre os envolvidos, o que proporciona maior compartilhamento de recursos materiais e humanos; facilitação da oferta de serviços com base nas necessidades de aprendizagem acadêmica e social dos alunos; desenvolvimento de programas de intervenção efetivos e criativos; oportunidade entre os envolvidos de aumentar e melhorar seu conhecimento conceitual e tecnológico, assim como suas habilidades 
interpessoais e suas atitudes intrapessoais (Idol, Nevin, \& Paolucci-Whitcomb, 2000). No que diz respeito aos benefícios para os pais, especificamente, eles podem aprender maneiras novas e mais eficazes de disciplinar seus filhos, entender as intervenções realizadas na escola, contribuindo com sua realização, e diminuir a tensão sobre a criação dos filhos. Além disso, o processo de CCE com os pais é uma chance para os profissionais os perceberem como parte da solução e não do problema (Kampwirth, 2003).

Upshur, Wenz-Gross e Reed (2009) desenvolveram um estudo cujo objetivo foi avaliar um programa de intervenção, baseado na CCE, dirigido para crianças consideradas em situação de risco, seus professores e pais. $\mathrm{O}$ estudo foi realizado em cinco escolas de Educação Infantil e contou com a participação de 37 professores, 47 familiares e 136 alunos, com idade entre 3 a 5 anos e identificados com problemas de comportamento do tipo externalizante. Dos 136 alunos, apenas 47 participaram da intervenção, sendo que os 89 alunos restantes não tiveram a autorização dos pais e fizeram parte do grupo controle não equivalente. Três consultores foram recrutados, treinados e indicados para prestar consultoria nas escolas. Quanto aos familiares, o estresse materno foi avaliado por meio do instrumento Parenting Stress Index-Short Form, também foi aplicado o instrumento The Parenting Scale para avaliar as habilidades parentais das mães. A satisfação dos familiares com a intervenção foi avaliada por meio de um questionário fechado composto por itens que investigavam os seguintes aspectos: impacto dos serviços no comportamento da criança e no seu desenvolvimento; grau em que as orientações fornecidas ajudaram os familiares a administrar o comportamento de seus filhos; grau em que a intervenção os ajudou a ficar mais próximos de seus filhos e a melhorar o relacionamento familiar; sentimento dos familiares em relação à participação na intervenção.

Ainda no referido estudo, o programa oferecido teve duração de três anos e, em relação à intervenção voltada para os familiares, os seguintes procedimentos foram desenvolvidos: a) consultoria com os pais e terapia familiar, visando orientá-los acerca de maneiras de disciplinar e apresentar regras aos filhos; b) mediação de encontros entre familiares e professores; c) orientação para os familiares sobre como procurar por outros recursos e serviços quando necessário. Além disso, foi realizado um trabalho individual em sala de aula e sessões de terapia individual com os alunos. A análise dos dados referente à amostra de 19 crianças do grupo experimental e 19 do grupo controle revelou que a intervenção foi associada à redução dos comportamentos agressivos, do comportamento não adaptativo e também ao aumento de comportamentos adaptativos. No entanto, não foi verificada mudança estatisticamente significativa quanto ao nível de estresse apresentado pelos familiares participantes, assim como quanto às habilidades parentais (Upshur et al., 2009).

Considerando a influência que os fatores familiares exercem na ocorrência de problemas de comportamento e também os benefícios que intervenções baseadas no modelo de CCE podem alcançar, o objetivo do estudo foi desenvolver, implementar e avaliar um programa de intervenção para familiares, com base no modelo de Consultoria Colaborativa Escolar, voltado para prevenir problemas de comportamento.

\section{Método}

Local

O estudo foi realizado em uma escola municipal de Ensino Fundamental localizada em um bairro da periferia de uma cidade de médio porte do interior do estado de São Paulo. Tendo em vista o caráter preventivo da intervenção a ser implementada, definiu-se que o estudo teria como alvo as três salas de $1^{\circ}$ ano, que seriam a porta de entrada dos alunos na escola.

\section{Participantes}

Participaram do estudo 18 familiares (15 mães, um pai e duas avós que possuíam a guarda legal de seus netos) de alunos do $1^{\circ}$ ano do Ensino Fundamental. A idade dos familiares variou entre 23 e 56 anos ( $\mathrm{DP}=7,2 \mathrm{e} \mathrm{Md}=34)$. Quanto à escolaridade, 50\% dos familiares apresentavam Ensino Médio completo, 28\% Ensino Fundamental incompleto, 17\% Ensino Fundamental completo e 5\% Ensino Médio incompleto. Embora os familiares de todos os alunos das salas de 1o ano tenham sido 
convidados para participar da pesquisa, apenas 18 aceitaram o convite.

\section{Instrumentos}

Foi utilizado o Inventário de Estilos Parentais (IEP) (Gomide, 2006) e um roteiro de entrevista semiestruturada elaborado especialmente para este estudo. 0 roteiro de entrevista teve como foco levantar a opinião dos familiares sobre as reuniões realizadas, assim como as mudanças no comportamento do filho e no relacionamento familiar após a intervenção.

O IEP tem como objetivo avaliar a maneira como os pais educam seus filhos. Contém 42 questões correspondentes a sete práticas educativas: duas positivas (monitoria positiva e comportamento moral) e cinco negativas (punição inconsistente, negligência, disciplina relaxada, monitoria negativa e abuso físico). 0 instrumento apresenta duas formas, sendo que em uma delas os pais respondem sobre as práticas educativas adotadas em relação ao filho (Práticas educativas paternas e maternas), e na outra forma o filho responde sobre as práticas educativas parentais. No estudo, foi utilizada apenas a forma Práticas educativas paternas e maternas (Gomide, 2006).

\section{Procedimentos éticos}

O estudo foi aprovado pelo Comitê de Ética em Pesquisa com Seres Humanos da Universidade Federal de São Carlos, protocolo n. CAAE 1003.0.000.135-08, parecer n. 247/2008, em 6 de junho de 2008. Todos os participantes assinaram um Termo de Consentimento Livre e Esclarecido, declarando sua concordância em participar da pesquisa.

\section{Procedimentos de coleta de dados}

0 estudo foi dividido em três etapas. Na etapa 1 (pré-teste), o IEP foi aplicado junto aos familiares participantes de forma coletiva. Após os participantes terem preenchido o IEP, o programa de intervenção preventiva teve início (etapa 2). A intervenção preventiva com os familiares realizou-se por meio de oito encontros, nos quais foram abordados temas relacionados às práticas parentais, conforme a Quadro 1 . 0 conteúdo das reuniões baseou-se em Gomide (2004; 2006) e Weber (2007).

Os encontros aconteceram quinzenalmente em uma das salas de aula da escola na qual o estudo foi conduzido, e tiveram duração aproximada de uma hora e meia. Os participantes foram estimulados a apresentar situações-problema que eles enfrentavam em suas casas sobre os temas abordados para que, em conjunto, possíveis soluções pudessem ser levantadas. Dessa forma, embora os encontros tivessem temas predefinidos, realizaram-se discussões conforme a demanda dos participantes.

De acordo com a disponibilidade de horário apresentada pelos familiares, formaram-se quatro grupos. Uma das mães (F6) reuniu-se individualmente com a pesquisadora pela manhã, como será explicado posteriormente. Quanto à assiduidade, F3 e F18 não compareceram, respectivamente, à quarta e à sétima reunião. Os demais participantes não apresentaram faltas.

Todos os participantes receberam uma pasta na qual podiam arquivar as apostilas distribuídas em cada encontro. As apostilas continham um resumo, em forma de tópicos, do conteúdo abordado nos encontros. Os conteúdos foram apresentados nas apostilas de forma clara e compreensível para que

\section{Quadro 1 - Organização da intervenção preventiva oferecida aos familiares}

\begin{tabular}{|c|c|c|}
\hline Encontro & Tema & Tarefa \\
\hline $1 \stackrel{0}{0}$ & $\begin{array}{l}\text { A importância de amar os } \\
\text { filhos }\end{array}$ & \\
\hline $2^{\circ}$ & $\begin{array}{l}\text { Regras são necessárias - } \\
\text { parte } 1\end{array}$ & \\
\hline $3^{\circ}$ & $\begin{array}{l}\text { Regras são necessárias - } \\
\text { parte } 2\end{array}$ & $\begin{array}{l}\text { Cartões com } \\
\text { as regras }\end{array}$ \\
\hline $4^{\circ}$ & A educação consistente & \\
\hline $5^{0}$ & Não faça uso de punição física & $\begin{array}{l}\text { Fichas de } \\
\text { bom compor- } \\
\text { tamento }\end{array}$ \\
\hline $6^{\circ}$ & $\begin{array}{l}\text { O melhor é usar consequên- } \\
\text { cias positivas }\end{array}$ & \\
\hline $7 \stackrel{0}{ }$ & $\begin{array}{l}\text { Devemos monitorar os filhos } \\
\text { de maneira positiva }\end{array}$ & \\
\hline $8^{0}$ & Fornecer modelo moral & \\
\hline
\end{tabular}

Fonte: Dados da pesquisa. 
os participantes, e também os demais familiares que moravam com o aluno, pudessem ter contato com os assuntos abordados.

No primeiro encontro discutiu-se com os familiares sobre como é importante demonstrar para os filhos o amor e o carinho que os pais sentem por eles, valorizando o esforço e os comportamentos positivos que eles apresentam, de modo a contribuir para a construção da autoestima.

A necessidade de estabelecer limites e de ensinar regras para os filhos foi o tema do segundo e terceiro encontros. No segundo encontro foi explicado que regras e limites são importantes para ensinar os filhos a distinguir o que é certo e o que é errado e para que eles se sintam seguros. Depois disso, solicitou-se que os familiares selecionassem aproximadamente cinco regras para apresentar aos filhos. Nesse momento, foi comentado que estabelecer um número elevado de regras é ruim porque os filhos ficam saturados e deixam de prestar atenção em muitas delas. Além disso, para os pais é mais difícil fiscalizar e fazer cumprir as regras quando elas existem em grande número. Salientou-se também que as regras não podem ser muito rígidas porque, dessa forma, as chances de elas serem desrespeitadas aumentam e, consequentemente, a possibilidade de os pais permitirem o descumprimento da regra é grande.

No terceiro encontro os participantes receberam cartões feitos com cartolina branca plastificada, nos quais estava impressa uma figura representativa de cada uma das regras escolhidas e também imãs para que os cartões pudessem ser afixados na geladeira. Os participantes receberam a instrução de fazer uma reunião familiar e, de maneira calma e clara, apresentar as regras que, a partir daquele momento, deveriam ser seguidas na casa, explicando a razão pela qual aquela regra estava sendo estabelecida. Os pais também receberam a orientação de elogiar e incentivar os filhos quando eles cumprissem as regras estabelecidas. Por outro lado, foi explicado que regras não cumpridas deveriam ser seguidas de uma consequência negativa que não poderia provocar dor, privar o filho de suas necessidades básicas e nem do carinho dos pais.

0 quarto encontro abordou o tema da educação consistente. Os pais foram orientados a deixar claro para os filhos que comportamentos adequados seriam valorizados e que, por outro lado, comportamentos inadequados seriam punidos. A importância da coerência entre os pais também foi abordada nesse encontro, já que essa era uma das queixas das mães.

As consequências adversas da punição constituíram o tema do quinto encontro, no qual houve a explicação de que agressão física, xingamentos, ameaças ou humilhação não deveriam ser aplicadas como métodos educativos, já que não ensinam para a criança o que ela faz de errado e nem a maneira correta de se comportar. Além disso, ao fazer uso de tais práticas, os pais apenas ensinam que a violência pode ser usada como meio para resolver problemas. Também foram descritas aos familiares algumas emoções negativas que os filhos podem sentir quando sofrem violência física ou psicológica, tais como raiva, medo, culpa e vergonha. No encontro os pais aprenderam alguns exercícios de autocontrole para usarem em momentos nos quais os filhos fazem alguma coisa errada que os deixa com muita raiva.

No quinto encontro os pais também receberam como tarefa as "fichas de bom comportamento", que consistiam em pequenos cartões de papel colorset que deveriam ser entregues aos filhos no final do dia, quando eles tivessem obedecido às regras estabelecidas. Na sexta-feira à noite os pais deveriam somar os cartões e o prêmio seria dado durante o final de semana. 0 número de cartões que cada criança teria que alcançar foi estabelecido em comum acordo entre pesquisadora e familiares, de acordo com as características de cada criança. No caso de pais com mais de um filho, determinou-se que os cartões de todos os filhos deveriam ser somados. Os pais receberam a instrução de presentear os filhos com um passeio em família ou então com um momento em família na própria casa, com jogos escolhidos pela criança ou desenhos. Deixou-se claro que o importante era que todos tivessem um momento divertido em família.

No sexto encontro foi explicado que prestar atenção apenas no que os filhos fazem de errado aumentava a chance de eles continuarem se comportando mal, já que com esse comportamento eles obtinham a atenção dos pais. Por isso, embora fosse fundamental supervisionar comportamentos inadequados, os pais deveriam utilizar consequências positivas diante de bons comportamentos.

0 sétimo encontro teve como tema a monitoria positiva. Discutiu-se o quanto é prejudicial fazer uso de supervisão estressante, vigiando e fiscalizando os filhos de modo exagerado e repetindo várias 
vezes as mesmas instruções. Em vista disso, os pais foram orientados a substituir a supervisão estressante pela monitoria positiva. Além disso, discutiu-se a importância de conversar amistosamente com os filhos para saber sobre o dia deles e colocar-se à disposição para resolver alguma dificuldade.

0 modelo moral constituiu o tema apresentado no oitavo e último encontros, nos quais foi explicado que uma das principais formas pela qual as crianças aprendem é observando e imitando pessoas próximas a ela. Em vista disso, os pais receberam a orientação de se comportar como eles gostariam que os filhos se comportassem, de modo a ensinar comportamentos adequados. Os pais também receberam a instrução de incentivar o comportamento moral de seus filhos, lembrando-os de utilizar palavras cordiais e valorizando a justiça, a amizade e o respeito ao próximo e às leis.

Embora, de modo geral, a intervenção com os familiares tenha se desenvolvido conforme apresentado, no caso de um familiar (F6) foram necessárias reuniões individuais devido ao elevado índice de comportamento internalizante apresentado por um de seus filhos. Segundo relato da professora, o aluno era extremamente retraído, não interagia com ela, com os colegas e não participava das atividades. Ele reclamava constantemente de dor de cabeça e dor de barriga e pedia para ir embora para casa.

Com o objetivo de entender o comportamento do aluno e encontrar possíveis soluções para o problema, o primeiro encontro com F6 consistiu em uma conversa sobre a maneira como ela interagia com seu filho em casa. Nesse encontro a mãe relatou que o filho teve uma parada respiratória quando ainda era recém-nascido. Embora a criança nunca mais tenha apresentado qualquer problema grave de saúde, ela mudou sua maneira de agir com ele depois desse episódio, educando-o de maneira superprotetora. A pesquisadora explicou para a mãe que o comportamento dela em relação ao filho teria que mudar e orientou para que ela, gradualmente, deixasse que o filho começasse a ter mais autonomia em suas atividades de vida diária. Para tanto, a pesquisadora selecionou três das atividades de vida diária da criança (hora de dormir, alimentação e banho) e estipulou passos graduais para que a mãe pudesse seguir de modo a promover a autonomia do filho. Nos encontros da pesquisadora com F6, além das instruções anteriormente descritas, os mesmos conteúdos das reuniões com os familiares foram abordados, embora de forma individual, assim como as duas tarefas (cartões com regras e fichas de bom comportamento).

Após a realização do programa de intervenção, ele foi avaliado com a reaplicação do IEP e do roteiro de entrevista semiestruturada (etapa 3). Cabe explicar que o roteiro de entrevista foi aplicado por meio de uma reunião de grupo focal realizada com os familiares. 0 objetivo dessa reunião foi obter dados sobre a validade social do programa de intervenção, assim como obter dados qualitativos sobre os seus efeitos.

Os dados obtidos por meio do IEP foram tabulados utilizando-se a folha de resposta do instrumento (Gomide, 2006). Quanto ao grupo focal, a reunião foi gravada em fita VHS e, posteriormente, transcrita. Para analisar as transcrições foi realizada análise qualitativa, utilizando-se a análise de conteúdo proposta por Bardin (1977).

\section{Resultados}

O impacto do programa de intervenção foi avaliado de forma quantitativa e qualitativa, conforme descrição a seguir.

\section{Avaliação quantitativa do programa de intervenção}

Procurou-se verificar diferenças estatisticamente significativas entre o pré e o pós-teste no que diz respeito às práticas parentais e também em relação ao índice de estilo parental (iep). Para tanto, foi aplicado o teste de MANOVA. Como pode ser observado na Tabela 1, houve aumento estatisticamente significativo no índice de estilo parental (iep), obtido como resultado da aplicação do IEP $(\mathrm{F}(144 ; 17)=$ $20,4 \mathrm{p}<0,001$ ).

Especificamente, houve aumento significativo no que diz respeito aos dois comportamentos relacionados com o estilo parental positivo, monitoria positiva $(\mathrm{F}(8,12 ; 17)=7,111 \mathrm{p}<0,05)$ e comportamento moral $(\mathrm{F}(4 ; 17)=8,5 \mathrm{p}<0,05)$. Quanto aos comportamentos relacionados com o estilo parental negativo, houve diminuição estatisticamente significativa em dois deles: disciplina relaxada ( $\mathrm{F}$ $(10,028 ; 17)=5,25 p<0,05)$ e monitoria negativa $(F(23,361 ; 17)=9,89 p<0,01)$. 
Tabela 1 - Estilos parentais apresentados pelos familiares no pré e pós-teste

\begin{tabular}{lcccccc}
\hline \multirow{2}{*}{ Escalas } & \multicolumn{2}{c}{ Pré-teste } & \multicolumn{2}{c}{ Pós-teste } & \multicolumn{2}{c}{ MANOVA } \\
\cline { 2 - 7 } & $\mathbf{M}$ & DP & M & DP & F & gl \\
\hline Monitoria positiva & 10,11 & 1,84 & 11 & 1,53 & $8,12^{*}$ & $1 ; 18$ \\
\hline Comportamento moral & 10,5 & 1,5 & 11,17 & 1,1 & $8,5^{*}$ & $1 ; 18$ \\
\hline Punição inconsistente & 3,39 & 2,03 & 3,28 & 1,84 & ns & ns \\
\hline Negligência & 1,72 & 1,64 & 2,28 & 2,03 & ns & ns \\
\hline Disciplina relaxada & 3,78 & 2,04 & 2,72 & 1,60 & $5,25^{*}$ & $1 ; 18$ \\
\hline Monitoria negativa & 7,44 & 1,85 & 5,83 & 2,38 & $9,89^{* *}$ & $1 ; 18$ \\
\hline Abuso físico & 2 & 1,75 & 1,72 & 1,67 & ns & ns \\
\hline Iep & 2,28 & 7,07 & 6,28 & 7,15 & $20,4^{* * *}$ & $1 ; 18$
\end{tabular}

Legenda: ${ }^{*} \mathrm{p}<0,05 ;{ }^{* *} \mathrm{p}<0,01 ;{ }^{* * *} \mathrm{p}<0,001 ; \mathrm{ns}=$ não apresenta diferenças estatisticamente significativas.

Fonte: Dados da pesquisa.

Quanto ao valor do iep, de acordo com a Gráfico 1 , a maior parte dos participantes apresentou, antes da intervenção, estilo parental regular com presença de práticas parentais positivas, mas também presença de práticas negativas: 12 familiares (F1, F2, F5, F6, F8, F9, F10, F12, F13, F14, F15 e F16) apresentaram iep com valor entre zero e oito. Ainda antes da intervenção, cinco familiares (F4, F7, F11, F17 e F18) apresentaram iep com valor negativo, indicando prevalência de práticas parentais negativas, 0 que caracteriza estilo parental de risco. Apenas um dos participantes (F3) apresentou iep maior que 11 (iep =13), indicando presença marcante das práticas parentais positivas e ausência das práticas negativas, o que caracteriza estilo parental ótimo.

Os resultados obtidos após a intervenção indicaram que, com exceção das participantes F4 e F6, houve melhora no iep dos familiares. No caso de F4, embora a participante tenha apresentado aumento no índice de comportamento moral e diminuição no índice de disciplina relaxada, houve aumento nos índices de negligência e monitoria

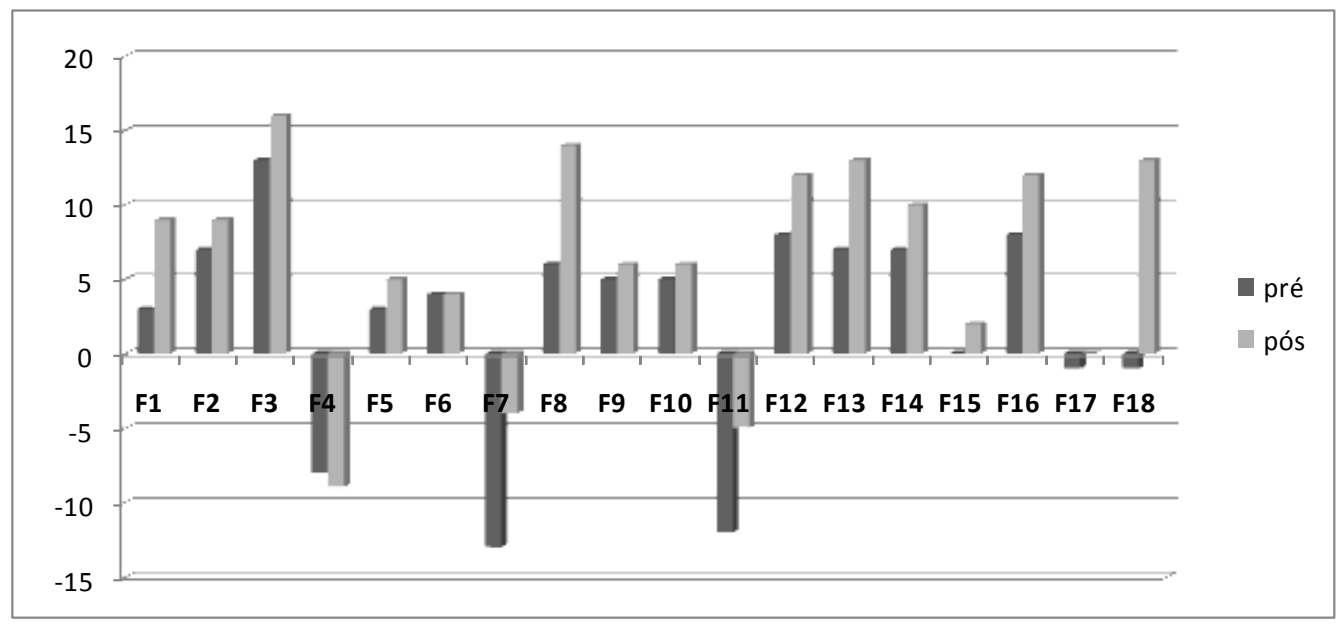

Gráfico 1 - Índice de estilo parental alcançado pelos familiares no pré e pós-teste Fonte: Dados da pesquisa. 
negativa, resultando em diminuição de um ponto no valor total do iep. Quanto à participante $\mathrm{F} 6$, o valor do iep não apresentou alteração antes e depois da intervenção.

\section{Avaliação qualitativa do programa de intervenção}

Por meio de reunião de grupo focal foi possível levantar quatro categorias: aspectos favoráveis da intervenção; aspectos desfavoráveis da intervenção; mudança no comportamento dos familiares; mudança no comportamento do filho. Como a técnica de grupos focais prevê a troca de informações, foi utilizado o sinal de pontuação barra (/) para indicar a interação entre os participantes nos diálogos. Cabe destacar que nos grupos focais as falas dos participantes são tomadas como a opinião de todo o grupo, com exceção dos relatos que representam casos específicos.

\section{Aspectos favoráveis da intervenção}

A intervenção foi avaliada positivamente pelos familiares, pois eles destacaram que foi possível conhecer a maneira como seus filhos pensam e agem, e isso os ajudou a lidar com mais facilidade e de maneira mais eficaz com seus filhos.

Acho que deu pra conhecer um pouquinho como eles são, como eles pensam, saber a hora que eles estão precisando da gente ou então quando eles estão fazendo graça.

[...] ajudou a gente a lidar com os filhos./A gente aprendeu a lidar com eles porque tinha coisa que a gente fazia e tinha um jeito mais simples de fazer. Ficou mais fácil agora.

De maneira específica, os participantes destacaram como aspectos favoráveis a flexibilidade de horários para a realização das reuniões e a pertinência dos temas selecionados, já que situações cotidianas foram abordadas.

No começo, a noite não ia dar mesmo. Se tivesse continuado só a noite não ia dar. Mas de manhã deu certo.

Acho que foi falado o que a gente precisava. $O$ dia a dia mesmo./Eu não senti falta de nada.

\section{Aspectos desfavoráveis da intervencão}

Foram levantados como aspectos desfavoráveis o fato de a intervenção ter focalizado apenas os familiares dos alunos do $1^{\circ}$ ano e não ter previsão de continuidade para o ano seguinte. Além disso, os familiares indicaram que as reuniões poderiam ter sido realizadas com frequência semanal ao invés de quinzenal.

Acho que o ruim foi que não teve pra todas as séries. Poderia ter sei lá, até o quinto ano/ia ser bom.

Acho que o ruim é que não tem continuidade, né. $O$ ano que vem não vai ter, seria uma boa/Eu acho que podia ter sido toda semana.

\section{Mudanças no comportamento dos familiares}

Os familiares indicaram ter aprendido a ter mais paciência e também a se acalmar antes de resolver situações conflituosas com os filhos, evitando assim agressões físicas. Também foi relatado que eles passaram a conversar mais com os filhos, a demonstrar mais interesse pela rotina deles e a prestar mais atenção no que eles diziam, como se comportavam e como se relacionavam com outras crianças.

Eu sempre me dei bem com eles, sabe. Mas agora tem certas coisas que a gente fica mais ligada, a gente presta mais atenção, como é a conversa deles, como eles tão se relacionando com outras crianças, começa a prestar atenção nisso também. Também quando eles chegam da escola eu pergunto "e aí, como foi hoje?". Sempre eles me falam. Sempre foi assim. Contam "hoje eu fiz isso, hoje eu fiz aquilo, hoje tava chato". Só que agora eu comecei a prestar mais atenção.

Agora eu converso mais com ela. Todo dia eu pergunto "como foi a escola?" "o que você fez hoje?"

Além disso, segundo os relatos obtidos, os familiares passaram a emitir os seguintes comportamentos: retirar a atenção do filho quando ele ficava emburrado sem apresentar motivo para isso; ser consistente e firme diante de comportamentos inadequados; evitar fazer uso de supervisão 
estressante, caracterizada pela exagerada vigilância e por um número grande de instruções repetitivas; ter momentos de lazer com os filhos.

Às vezes minha filha fica brava e emburra. Eu não vou atrás, eu deixo ela emburrada até ela melhorar.

Eu acho que, analisando, eu era muito mole. Eu deixava muito assim solto. Agora eu comecei a ser mais firme com eles.

Deu pra aprender também como chamar a atenção deles, né. No dia a dia a gente ficava falando, falando e não adiantava nada. Agora a gente sabe como fazer, o que falar.

Também comecei a vir com as duas a noite na quadra, deixo elas brincando na quadra.

Uma das mães (F9) disse que o marido também modificou o seu comportamento com a intervenção, já que ela compartilhava o conteúdo das reuniões com ele por meio das apostilas entregues. Segundo F9, ela e o marido passaram a dividir a responsabilidade de educar as filhas e a apoiar as decisões um do outro.

Antes eu falava uma coisa e meu marido outra. Eu falava que não e ele falava "ah, vem cá que o pai deixa". Agora não. Ele fala "o que sua mãe te falou?", "o que sua mãe te falou, não é isso? Então obedeça a sua mãe". Ele já tá mais, sabe, porque a gente conversou muito também. Então tá indo os dois juntos. Então até meu marido mudou [...] Então ele também tem autoridade agora. Ele mudou muito [...] eu chegava em casa, mostrava os papéis que você dava e falava "olha aqui como que é".

A participante $\mathrm{F} 4$ relatou que o relacionamento entre ela e os netos continua difícil, mas afirma que melhoras estão acontecendo lentamente: Com os dois eu acho que ainda tá difícil, mas eu acho que devagar tá melhorando.

\section{Mudanças no comportamento dos filhos}

Segundo os familiares, o comportamento dos filhos melhorou depois da intervenção, já que eles passaram a obedecer mais prontamente às ordens dos pais, sem que estes precisassem fazer uso de agressões físicas. Além disso, eles ficaram mais atentos para as regras da casa, obedecendo-as.

Outra mudança observada foi o fato de os filhos reconhecerem seu erro após ficar de castigo e se desculpar com os pais pelo que fizeram. Também foi mencionado que os filhos estavam brigando menos entre si. F1 relatou ainda que a filha, bastante retraída, estava mais extrovertida.

É importante destacar que as mudanças observadas referem-se a todos os filhos e não apenas aos alunos do $1^{\circ}$ ano, que participaram diretamente da intervenção na escola.

Minha filha melhorou 100\%. Antes tudo que eu falava ela falava "não". Agora mudou. Agora eu só preciso falar uma vez. Independente de dar tapa. Antes ela funcionava muito no tapa.

Ela tá mais atenta as regras, tem coisa que eu não preciso mais ficar mandando.

Agora ela para pra pensar mais nas coisas, tipo que nem eu deixo de castigo e ela vem e pede desculpa. Ela fala assim "tá bom mãe, você me desculpa, eu não vou fazer mais". Aí eu pergunto "você sabe por que eu te deixei de castigo?" ela fala "eu sei mãe". Aí ela vem, me beija me abraça. Então eu acho que ela mudou bastante.

Eles melhoraram, tão mais obedientes, tão brigando menos um com o outro.

\section{Discussão}

A avaliação do impacto do programa de intervenção no comportamento dos familiares indicou que, de modo geral, houve aumento estatisticamente significativo no índice de estilo parental. Especificamente, observou-se melhora nos comportamentos referentes ao estilo parental positivo, monitoria positiva e comportamento moral. Quanto aos comportamentos referentes ao estilo parental negativo, foi observada diminuição estatisticamente significativa na disciplina relaxada e na monitoria negativa.

Resultados semelhantes foram observados por Rios (2006), em estudo que teve como objetivo avaliar os efeitos de um programa de intervenção com foco na prevenção de problemas comportamentais voltado para famílias de baixa renda. Após a intervenção, as mães participantes apresentaram 
aumento na emissão de classes de comportamentos parentais positivos. Além disso, elas também apresentaram decréscimo quanto ao uso de disciplina inconsistente, super-reatividade e verbalizações excessivas e inadequadas, sendo as três últimas práticas características da monitoria negativa.

Os resultados obtidos por meio da aplicação do IEP podem ser comparados aos resultados qualitativos, levantados por meio da reunião de grupo focal sobre as mudanças que os familiares observaram em seu próprio comportamento. Os familiares relataram ter aprendido a ser mais pacientes e a se acalmar para resolver situações-problema, evitando fazer uso de punição física. Nessa mesma direção, no estudo conduzido por Cia (2009), que teve como objetivo avaliar os efeitos de uma intervenção cujo foco foi o aprimoramento do envolvimento do pai e o estímulo de práticas parentais capazes de favorecer comportamentos pró-acadêmicos por parte dos filhos, $22,2 \%$ dos pais que participaram da intervenção oferecida (GE1 e GE2) relataram que passaram a tratar com mais facilidade os problemas enfrentados na educação de seus filhos.

Assim como no estudo de Cia (2009), no qual foi observado aumento na frequência de comunicação com os filhos entre os pais dos grupos GE1 e GE2, os familiares do presente estudo também indicaram que, a partir das discussões realizadas nos encontros quinzenais, eles passaram a dialogar mais com os filhos, demonstrando mais interesse pela rotina deles. Outra mudança no comportamento dos pais observada no estudo de Cia foi que $27 \%$ dos participantes dos grupos GE1 e GE2 modificaram a maneira de educar seus filhos. No presente estudo, essa mudança também foi observada, já que os familiares relataram ter deixado de reforçar comportamentos inadequados, passaram a adotar postura firme, a dar respostas consistentes frente aos comportamentos disruptivos, a evitar o uso de supervisão estressante e a planejar momentos de lazer com os filhos.

Além disso, resultados semelhantes foram encontrados no que diz respeito às mudanças de comportamento dos filhos. No estudo conduzido por Cia (2009), 15,9\% dos pais que participaram da intervenção apontaram que o filho estava mais obediente. No presente estudo, conforme indicado pelos resultados qualitativos, todos os familiares relataram que os filhos passaram a obedecer prontamente às ordens dos pais e às regras estabelecidas por eles quanto à rotina familiar. Além da obediência, no presente estudo os participantes apontaram como mudanças de comportamento os filhos reconhecerem seu erro após ficar de castigo e diminuição nas brigas entre os irmãos.

Ainda quanto aos resultados qualitativos obtidos por meio da reunião de grupo focal, a avaliação positiva que os familiares realizaram sobre o programa de intervenção precisa ser ressaltada, principalmente porque ela foi desenvolvida no ambiente escolar. Conforme aponta Sheridan e Gutkin (2000), promover mudanças nos ambientes nos quais os alunos estão inseridos (tais como escola, família e comunidade) constitui-se como um caminho significativo para ações preventivas. Segundo Carvalho (2008), a implementação de intervenções na comunidade educacional, com base na cooperação, maximiza a parceria entre os profissionais da escola e a família.

0 trabalho desenvolvido por Upshur et al. (2009) avaliou os efeitos de um programa de intervenção que ofereceu Consultoria Colaborativa Escolar aos familiares, assim como no presente estudo, e terapia familiar, com o objetivo de orientar os familiares sobre maneiras de disciplinar e apresentar regras aos filhos. No entanto, diferentemente dos resultados alcançados no presente estudo, os autores relataram que não foi verificada nenhuma mudança estatisticamente significativa quanto ao nível de estresse e habilidades parentais, embora resultados positivos tenham sido observados nas crianças que também foram alvo do programa de intervenção.

É importante discutir ainda, que, de maneira específica, a intervenção parece não ter produzido melhora nas práticas parentais de duas participantes: F4 e F6. A participante F4 apresentou piora em seu índice de estilo parental. Observando cada uma das práticas investigadas, a participante apresentou aumento no índice de comportamento moral e diminuição no índice de disciplina relaxada. Entretanto, houve aumento nos índices de negligência e monitoria negativa, resultando em diminuição de um ponto no valor total do iep. Na reunião de grupo focal, F4 declarou que o relacionamento entre ela e os netos continuava difícil, mas afirmou que melhoras estavam acontecendo, embora lentamente.

Esse resultado pode ser explicado considerando-se o momento de crise pelo qual a família estava passando. No início do ano no qual o programa de intervenção foi realizado, a mãe abandonou os filhos mais velhos, que ficaram sob os cuidados da 
avó, F4. A avó demonstrava em seu discurso muita raiva pela filha e também o quanto cuidar dos netos era uma sobrecarga para ela. Considerando a situação delicada dessa família, e também a recomendação de Gomide (2006) de que familiares classificados em situação de risco devem receber intervenção terapêutica, em grupo ou individualmente, a pesquisadora discutiu com a assistente educacional pedagógica da escola sobre a possibilidade de encaminhar a avó e as duas crianças para atendimento psicológico clínico gratuito. 0 encaminhamento foi realizado e, no mês de julho, os três passaram a ser atendidos por estagiários do curso de Psicologia de uma universidade particular da cidade.

No caso de F6, não houve alteração no índice de estilo parental após a intervenção. É preciso considerar que a intervenção com F6 aconteceu em situações especiais, já que seu filho apresentou, antes da intervenção, um índice elevado de comportamento do tipo internalizante. Diante disso, a intervenção concentrou-se em modificar o comportamento de F6 no que dizia respeito ao comportamento superprotetor dela em relação ao seu filho, e as demais questões (demonstrar carinho pelos filhos, estabelecer regras, ser consistente, fazer uso de consequências positivas no lugar de punição física, monitorar os filhos de modo positivo e fornecer modelo moral) foram abordadas de maneira secundária.

Além disso, o fato de a intervenção com F6 ter acontecido individualmente, não possibilitou a troca de experiência dessa mãe com os demais participantes, ou seja, os temas não foram abordados com toda a riqueza com que foram abordados nos outros grupos. Apesar disso, as melhoras observadas em F6 que deixou de apresentar qualquer comportamento superprotetor e passou a valorizar a autonomia do filho - , e a consequente melhora no comportamento de seu filho na escola, indicam que a intervenção voltada para essa mãe foi bem-sucedida nesses aspectos que não foram medidos pelo instrumento IEP.

\section{Considerações finais}

Em vista dos resultados apresentados, é possível concluir que a Consultoria Colaborativa Escolar pode ser um modelo promissor para basear intervenções voltadas para melhorar práticas parentais e, consequentemente, prevenir a manifestação de problemas comportamentais na escola. Um aspecto importante a ser ressaltado é que os familiares observaram mudanças nos comportamentos de todos os filhos, e não apenas nos filhos que participaram do programa de intervenção (os alunos do 1o ano). Isso indica que o principal objetivo da intervenção voltada para os familiares foi alcançado, ou seja, promover melhoras no comportamento dos filhos por meio da modificação do ambiente familiar, desenvolvendo práticas parentais positivas. Essas práticas permitiram aos familiares estabelecer e fazer cumprir regras, responder aos comportamentos emitidos pelas crianças de modo consistente, fazer uso de consequências positivas ao invés do uso de punição física, demonstrar carinho e amor aos filhos por meio de ações, monitorar os filhos de modo positivo e fornecer modelo moral.

\section{Referências}

Bardin, L. (1977). Análise de conteúdo. Lisboa: Edições 70.

Carvalho, R. G. G. (2008). A dimensão relacional da intervenção dos serviços de psicologia nas escolas. Psicologia: Reflexão e Crítical, 21(1), 119-124.

Cia, F. (2009). Um programa para aprimorar envolvimento paterno: Impactos no desenvolvimento do filho. Dissertação de mestrado em Educação Especial não publicada, Universidade Federal de São Carlos, São Carlos.

Gomide, P. I. C. (2004). Pais presentes, pais ausentes: Regras e limites. Petrópolis: Vozes.

Gomide, P. I. C. (2006). Inventário de estilos parentais IEP: Modelo teórico, manual de aplicação, apuração e interpretação. Petrópolis: Vozes.

Idol, L., Nevin, A., \& Paolucci-Whitcomb, P. (2000). Collaborative consultation. Texas: Proed.

Kampwirth, T. J. (2003). Collaborative consultation in the schools: Effective practices for students with learning and behavior problems. New Jersey: Pearson Education.

Kauffman, J. M. (2005). Characteristics of emotional and behavioral disorders of children and youth (8. ed.). New Jersey: Pearson Educational. 